\title{
Dynamics of the large opening fire valves of dust explosions automatic localization systems
}

\author{
V. Eidukynas*, A. J. Poška**, V.Grigas**** \\ *Kaunas University of Technology, Studenty 56, LT-51424 Kaunas, Lithuania, E-mail: valdas.eidukynas@ktu.lt \\ **Vilnius Gediminas Technical University, Naugarduko g. 41, LT-03227 Vilnius, Lithuania, \\ E-mail: algimantas.poska@vgtu.lt \\ ***Kaunas University of Technology, Studentu 56,LT-51424 Kaunas, Lithuania, E-mail: vytautas.grigas@ktu.lt \\ cross $^{\text {ref }}$ http://dx.doi.org/10.5755/j01.mech.21.5.11759
}

\section{Introduction}

Organic dust (flour, bran, windmill, elevator, combined forage factory dust) and air mixtures (aerosols) originating during technological processes in the grain refinement companies are explosive. The explosion happens when there is a certain concentration of dust and enough thermal source temperature and energy

It was found that initial explosions are caused by heated due to friction or sparking deteriorated parts of technological equipment, extrinsic metal parts fallen into rotating technological machines and striking sparks, deteriorated electrical equipment and so on $[1,2]$. These initial explosions are usually weak, but the blast wave, travelling along technological equipment chambers and ductworks connecting them blows away dust from walls, the flame coming from behind ignites new aerosol masses and causes bigger explosions. If the wall of the technological devices or ductwork cannot withstand increased pressure and breaks down, the flame penetrates to production rooms where sediments of dust on edges of building structures, walls of technological devices and the floor usually exist. The blast wave raises them and the penetrated flame from technological devices or aspiration system ignites it. That is why explosions of destructive force happen breaking the glass of windows, damaging the technological devices and building structures, injuring or killing people [3, 4]. One of the largest recent accidents happened in 2013 spring in Irkutsk (Russia) [4]. Blast wave almost completely destroyed one of the local elevator manufactories. Experts have found that the cause of the accident was the explosion of organic dust.

To reduce the scale of accidents, the automatic dust explosion localization systems (ADELS) are employed. When the initial (weak) explosion is registered by ADELS pressure or temperature sensors, initial source of the explosion is localized by means of fire dampers fire dampers mounted in ductwork system and this way major accidents are avoided.

Therefore one of the main components of ADELS are the fire dampers - devices, installed in ducts and air transfer openings of an air distribution or smoke control systems to close automatically upon detection of heat. They also serve to interrupt migratory airflow, resist the passage of flame, and maintain the integrity of the fire rated separation [5]. Various design fire resistant dampers and smoke dampers are available on the market, and they may be single or multi-blade, round or square cut, mechanical with fusible element or electromechanical actuator (linear or rotary) $[6,7]$. Guillotine or slide-gate fire dampers ensure most effective (operative and tight) shut-off [7] because of their structural peculiarities: single monolithic blade supported by the entire perimeter (when shut). Linear motion of the fire dampers sliding plate type shutters is usually generated by pneumatic or linear electric drives. In this case blade may be matched with secondary element of the asynchronous linear induction motor (LIM) thus ensuring a high speed of the shutter and herewith operation of the damper [8-10]. To prevent malfunction of such fire dampers due to seizing of the blade plate affected by blast wave additional bearings can be used, installed in LIM inductors active zone [11] but it helps only when the blade itself is not deformed too much, and this condition may be met when damper is completely shut before pressure jump.

However, such dampers usually are usable in relatively small cross-sectional area ductworks only. When the duct cross-sectional area is large, damper shutting time increases and damper sheet metal blade stiffness decreases thus the damper may not close completely or lose tightness even if it was closed in time. Therefore the possibility to engage multi-blade slide-gate type fire dampers to control flows in large cross-sectional area ductworks should be analyzed.

This paper deals with the impact of explosion pressure on the various parameters (size ant thickness) slide-gate type fire damper sheet metal blade (shutting element) and dynamics of such fire damper operation (shut-off process) when localizing initial explosion.

\section{Slide-gate type fire dampers}

Design of the single blade slide-gate type fire damper for $L \times L=L^{2}$ size square cross-section ductwork is shown in the Fig. 1 . The blade 2 guided by frame 1 is actuated by LIM inductor 3 which three phase winding is connected to electric power supply source via terminal box 4 . To activate fire damper to localize initial explosion source the inductor windings are connected in parallel and LIM works like magnetically and electrically duplex. When the damper is to be used as technological, it is enough to feed only one of its windings. In this case the LIM works as a magnetically duplex but electrically oneway and the startup force of LIM decreases approximately 2 times. If LIM inductor windings are connected in serial, LIM startup force decreases even more.

Having the aim to shut larger cross-section ductwork the size of fire damper and correspondingly its blade may be increased, for example, to $2 L \times 2 L=4 L^{2}$ (Fig. 2), 
however in such case larger number of LIM inductors should be used because of larger mass of the blade. It increases due to larger size and thickness (the latter should be enlarged to ensure necessary stiffness of the blade affected by pressure of the blast wave.

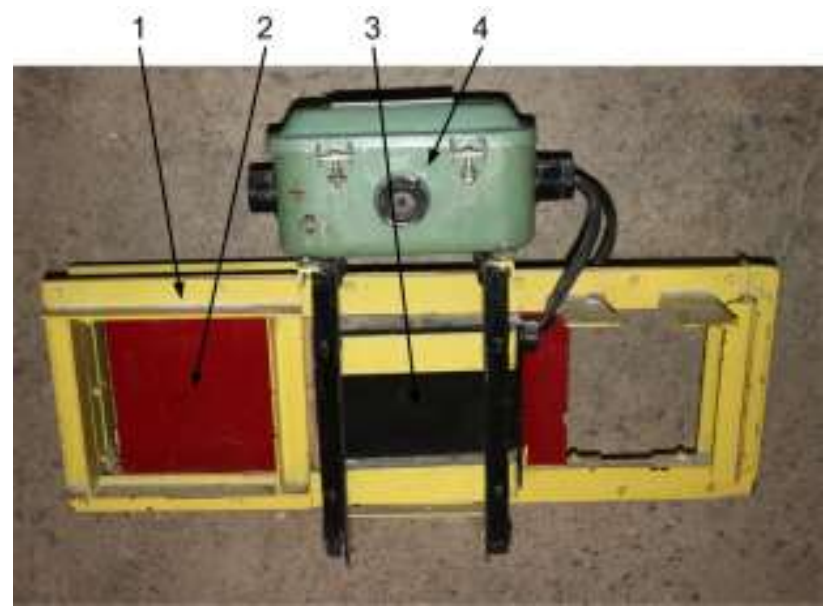

Fig. 1 Dust explosion localization system fire damper $\left(L \times L=L^{2} \quad\right.$ effective cross-section): 1 -frame; 2 -moving (LIM secondary) element (blade); 3 - LIM inductor; 4 - terminal box
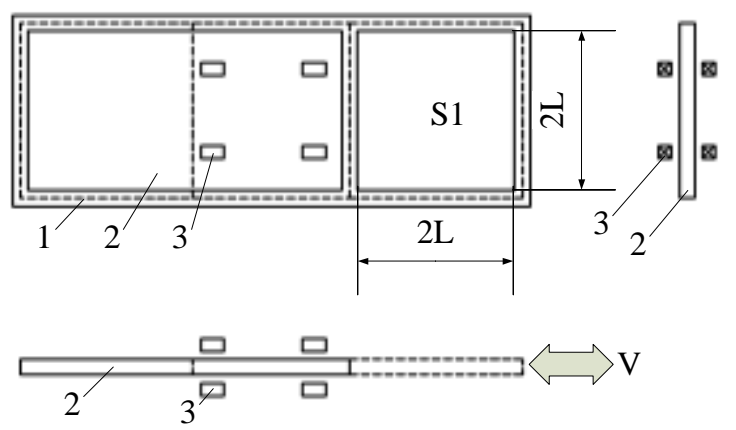

Fig. 2 Scheme of the $S 1=2 L \times 2 \mathrm{~L}=4 L^{2}$ effective crosssection fire damper with four electrically and magnetically duplex LIM: 1 - frame; 2 - moving (LIM secondary) element (blade); 3 - LIM inductors; $V-$ speed of moving (LIM secondary) element; $2 L-$ width and height of the technological channel blocked by fire damper

A multiple blade system may be offered as an alternative solution in which larger cross-section duct is shut by two or four blades moving parallelly or/and oppositely (Figs. 3 and 4). Fire damper with two parallelly moving blades (each having effective area $S 2=2 L \times L$, stroke $2 L$ ) is shown on Fig. 3, and damper with two oppositely moving blades (each having effective area $S 2=L \times 2 \mathrm{~L}$, stroke $-L$ ) is shown on Fig. 4 . In both cases the total effective area of the blades (and the cross-section area of the duct do be shut) is the same, $2 L^{2}$, but in the latter case the stroke of the blade is smaller in half, so such damper is able to localize the explosion in a shorter period of time.

In case when the cross-section of ductwork is even larger, a damper shown in Fig. 5 can be used, which has two pairs parallelly and oppositely moving (stroke $L$ ) blades (LIM secondary elements), each closing an area of size $L \times L=L^{2}$.
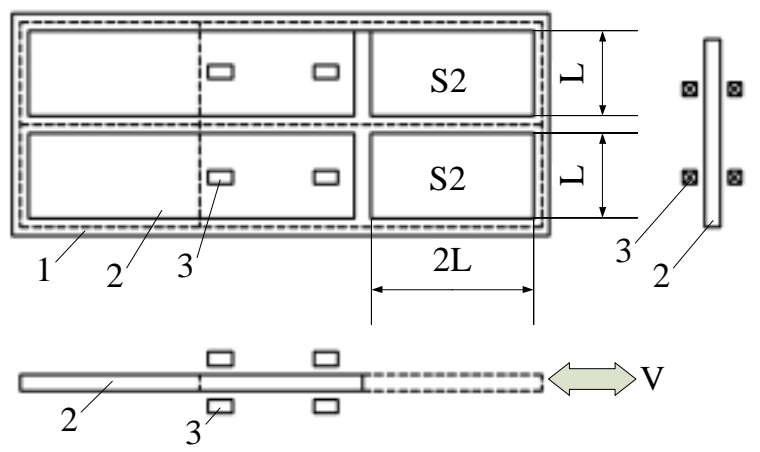

$\mathrm{a}$

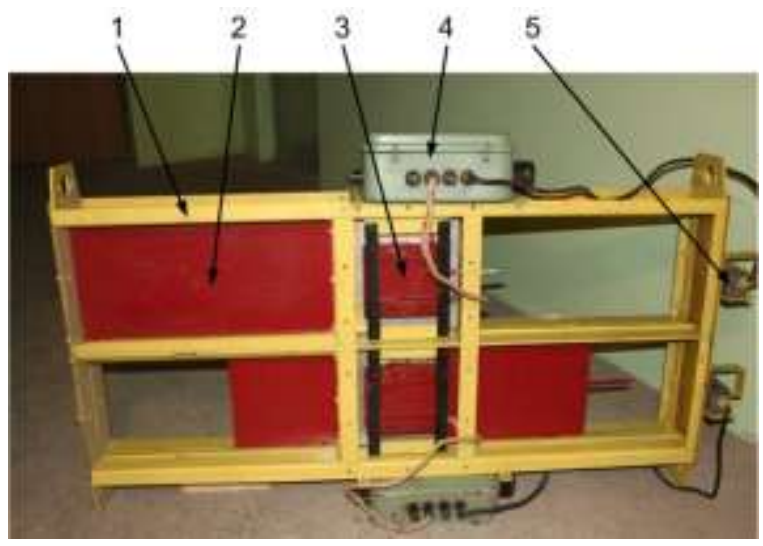

b

Fig. 3 Fire damper with the two parallelly moving LIM secondary elements (blades): a-scheme; $\mathrm{b}$ - common view: 1 - frame; 2 - moving (LIM secondary) element (blade); 3 - LIM inductor; 4 - terminal box; 5 - blade stroke (limit) switch

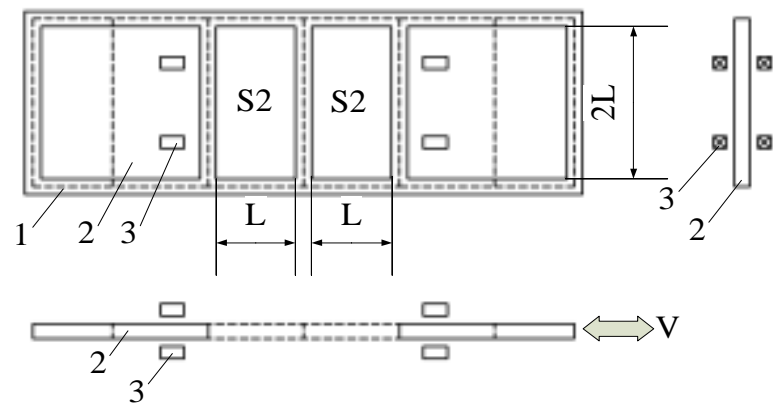

Fig. 4 Fire damper with the two oppositely moving LIM secondary elements (blades): 1 - frame; 2 - moving (LIM secondary) element (blade); 3 - LIM inductor

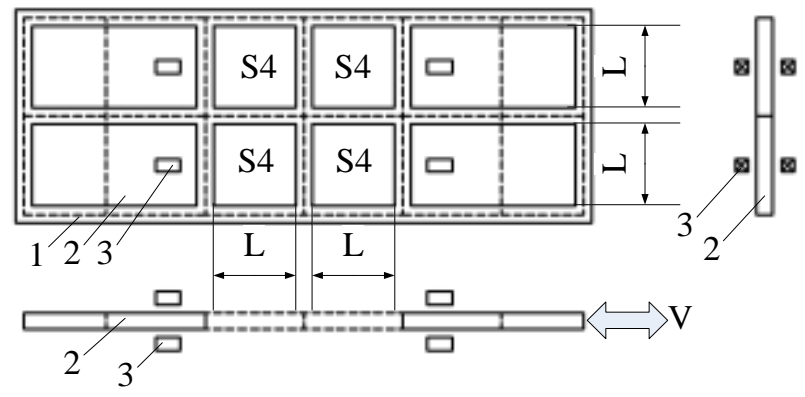

Fig. 5 Fire damper with the two parallelly and oppositely moving LIM secondary elements (blades): 1 -frame; 2 -moving (LIM secondary) element (blade); 3 - LIM inductor 


\section{Deformation of the fire dampers blades}

Having the aim to investigate the stress-strain state of the slide-gate type fire dampers blades under the effect of blast wave the geometrical models of the blades of $0,3 \times 0,3 \mathrm{~m}^{2}$ cross-section ductwork fire damper (Fig. 1) and enlarged cross-section $\left(1 \times 1 \mathrm{~m}^{2}\right)$ fire dampers were created by using SolidWorks 3D CAD software. Basing on them corresponding computational finite element models were developed by using SolidWorks Simulation finite element analysis software. In the latter case four different design fire dampers (Figs. 2, 3, 4 and 5) blades were modeled:

1. $1 \times 1 \mathrm{~m}^{2}$ - fire damper with single blade;

2. $1 \times 0,5 \mathrm{~m}^{2}-$ two blades (moving parallelly);

3. $0,5 \times 1 \mathrm{~m}^{2}-$ two blades (moving oppositely);

4. $0,5 \times 0,5 \mathrm{~m}^{2}-$ four blades (two pairs moving oppositely).

The deflection of all five designs blades were computed assuming that they are made of $6 \mathrm{~mm}$ thickness duralumin sheet, supported slidingly along the entire perimeter. The first, smallest fire damper blade was loaded by $25000 \mathrm{~N} / \mathrm{m}^{2}$ static pressure, and all four blades of the enlarged cross-section fire dampers were loaded by $50000 \mathrm{~N} / \mathrm{m}^{2}$ static pressure.

It was obtained, that under the effect of $25000 \mathrm{~N} / \mathrm{m}^{2}$ blast wave pressure the blade of $0,3 \times 0,3 \mathrm{~m}^{2}$ cross-section ductwork fire damper (pos. 2 on Fig. 1) deflects more than $7 \mathrm{~mm}$ (Fig. 6).

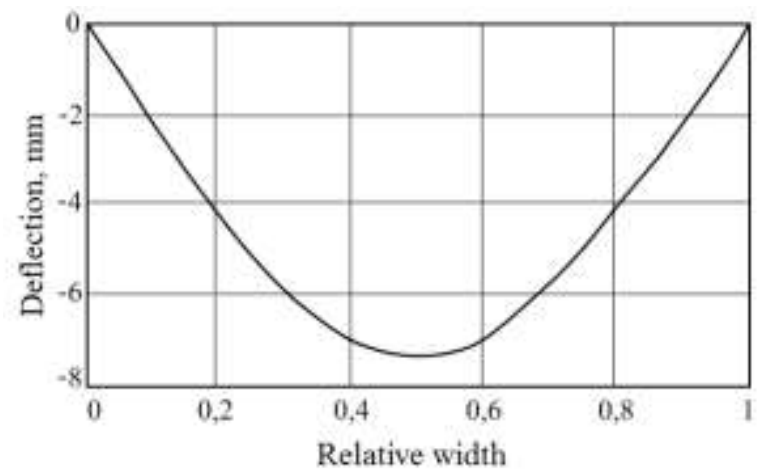

Fig. 6 Deflection of the $0,3 \times 0,3 \mathrm{~m}^{2}$ effective area fire damper $6 \mathrm{~mm}$ thickness duralumin blade affected by $25000 \mathrm{~N} / \mathrm{m}^{2}$ blast wave pressure

Curves representing deflection of all four blades of $0,3 \times 0,3 \mathrm{~m}^{2}$ effective area fire damper under the effect of $50000 \mathrm{~N} / \mathrm{m}^{2}$ blast wave pressure are shown on Fig. 7. It may be seen, that as it was to be expected the maximal deflection occurred in case of the largest size blade - approximately 14,5 mm (Fig. 7, curve No. 1). Almost in half smaller (near 8,5 mm, Fig. 7, curve No. 3) is deflection of $0,5 \times 1 \mathrm{~m}^{2}$ size blade (fire damper with the blades moving oppositely), and the smallest are deflections of smallest, $0,5 \times 0,5 \mathrm{~m}^{2}$, blade - a little bit more than $3 \mathrm{~mm}$ (Fig. 7 , curve No. 4). Such differences may be explained easily: the smallest deflection is obtained in case of smallest size blades, and when blades are of the same size (the 2 nd and the 3 rd cases, $1 \times 0,5 \mathrm{~m}^{2}$ and $0,5 \times 1 \mathrm{~m}^{2}$ size blades) the influence of boundary conditions becomes evident: deflection is smaller when guides supporting blade are closer to each other ( $1 \mathrm{~m}$ in cases 1 and 3 and $0,5 \mathrm{~m}$ in cases 2 and 4).

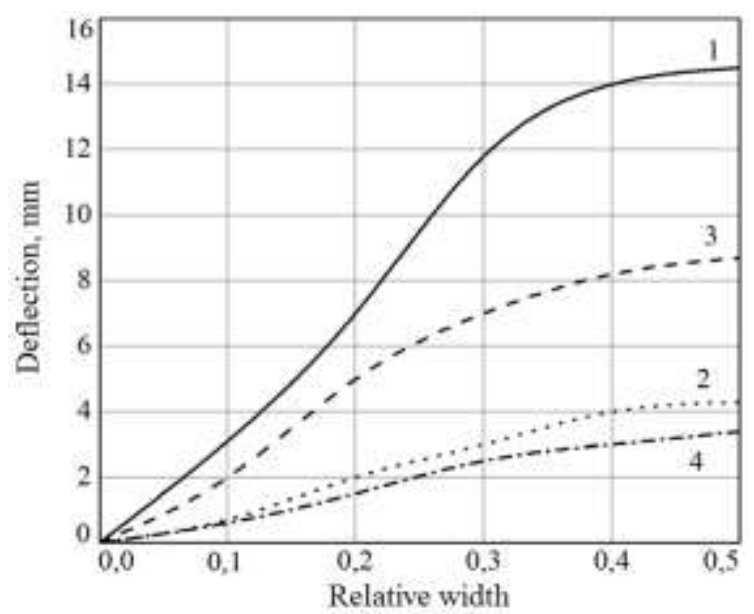

Fig. 7 Deflection of the $1 \times 1 \mathrm{~m}^{2}$ effective area fire damper $6 \mathrm{~mm}$ thickness duralumin blades under the $50000 \mathrm{~N} / \mathrm{m}^{2}$ blast wave pressure: $1-1 \times 1 \mathrm{~m}^{2}$ size blade; $2-1 \times 0,5 \mathrm{~m}^{2}$ size blade; $3-0,5 \times 1 \mathrm{~m}^{2}$ size blade; $4-0,5 \times 0,5 \mathrm{~m}^{2}$ size blade

In order to maximize shut speed of the fire damper the mass of the moving elements (blades) should be minimized, thus obtaining less inert system. Therefore an iterative computational analysis has been carried out resulting in thicknesses of the blades of all four designs fire dampers giving the same, $14,5 \mathrm{~mm}$ maximal deflection, characteristic to the largest, $1 \times 1 \mathrm{~m}^{2}$ size $6 \mathrm{~mm}$ thickness fire damper blade ( $1^{\text {st }}$ analyzed case) under the same loading $\left(50000 \mathrm{~N} / \mathrm{m}^{2}\right.$ blast wave pressure). It was obtained that thickness of the $0,5 \times 1 \mathrm{~m}^{2}$ (half size, vertical) blades moving oppositely (3rd case) may be three times smaller, $2 \mathrm{~mm}$. The smallest minimal thicknesses are in cases of two $0,5 \times 1 \mathrm{~m}^{2}$ size horizontal blades moving parallelly (2nd case) $-0,7 \mathrm{~mm}$, and $0,5 \mathrm{~mm}$ in 4th case (four $0,5 \times 0,5 \mathrm{~m}^{2}$ size blades). Such a drop of minimal blade thickness may also be determined by different boundary conditions: the smallest thickness of the blades is obtained when guides supporting them are closer to each other.

Blades of specified sizes and thicknesses described above are of the following masses: $m_{1}=16,2 \mathrm{~kg}$, $m_{2}=2,6 \mathrm{~kg}, m_{3}=0,81 \mathrm{~kg}, m_{4}=0,27 \mathrm{~kg}$, what means that less inert will be the smallest size, $0,5 \times 0,5 \mathrm{~m}^{2}$, blades, and the total mass of all four blades giving the same effective area as single $1 \times 1 \mathrm{~m}^{2}$ size blade is near 16 times smaller. Thus it may be supposed that it will be far easier to reach higher shut speed of the fire damper with such blades (this aspect is analyzed in the next section).

\section{Dynamics of the fire dampers}

To investigate dynamics of all four design fire damper a computer model of linear electric drive was built by means of Matlab Simulink software. Its block diagram is shown on Fig. 8, and block diagrams of its two main parts - Power Supply Disconnection (PSD) block and Resistance Force Evaluation (RFE) block (positions 1 and 2 on Fig. 8) are shown in more detail in Figs. 9 and 10 correspondingly. PSD block (Fig. 9) disconnects LIM power supply voltage (assigns 0 value) when moving element (blade) reaches edge of the hatch, that is $U=0$, when $S \geq l_{\text {hatch }}$.

The most important part of the computer model of 
fire damper linear electric drive is the RFE block (Fig. 10), which evaluates three forces, acting the blade of fire damper in the direction of its stroke: static resistance force (friction), dynamic resistance force caused by explosion and stoppage force, equivalent to the force of fire damper's blade impact to the frame edge.

Part 2.1 of RFE block models the static resistance forces when damper's blade is not affected by pressure of explosion wave:

$$
F_{s t}=k_{f r} m g
$$

where $m$ is mass of the blade; $k_{f r}$ is friction factor; $g$ is gravitational acceleration.

Part 2.2 of RFE block models the dynamic resistance force caused by explosion. This force is approximately proportional to the area of fire damper opening closed by protruding blade (in process of closing the damper), which in turn depends on blade traveled distance (displacement) $S$ :

$$
F_{d y n}=\mathrm{S} F_{e x p l}^{*}
$$

where $S$ is blade displacement; $F_{\text {expl }}^{*}$ is resistance force caused by explosion wave pressure per blade displacement unit, $\mathrm{N} / \mathrm{m}$.

Part 2.3 of RFE block models blade's edge impact to the guiding's frame body (or to the bumper) at the end of stroke. When the blade edge comes into contact with unmovable parts of the frame resistance force is increased to $100000 \mathrm{~N}$ thus simulating instantaneous halt, that is when $l_{\text {stroke }}-S \leq 0, F_{\text {stop }}=100000 \mathrm{~N}$.

Part 2.4 of RFE block models resultant (effective) force: here all resistance forces are subtracted from driving force generated by LIM.

Part 2.5 of RFE block models blade (connected to LIM secondary element) stopping: when $v \leq 0$ and $F_{\text {efective }} \leq 0, a=0$ ( $a$ is blade acceleration).

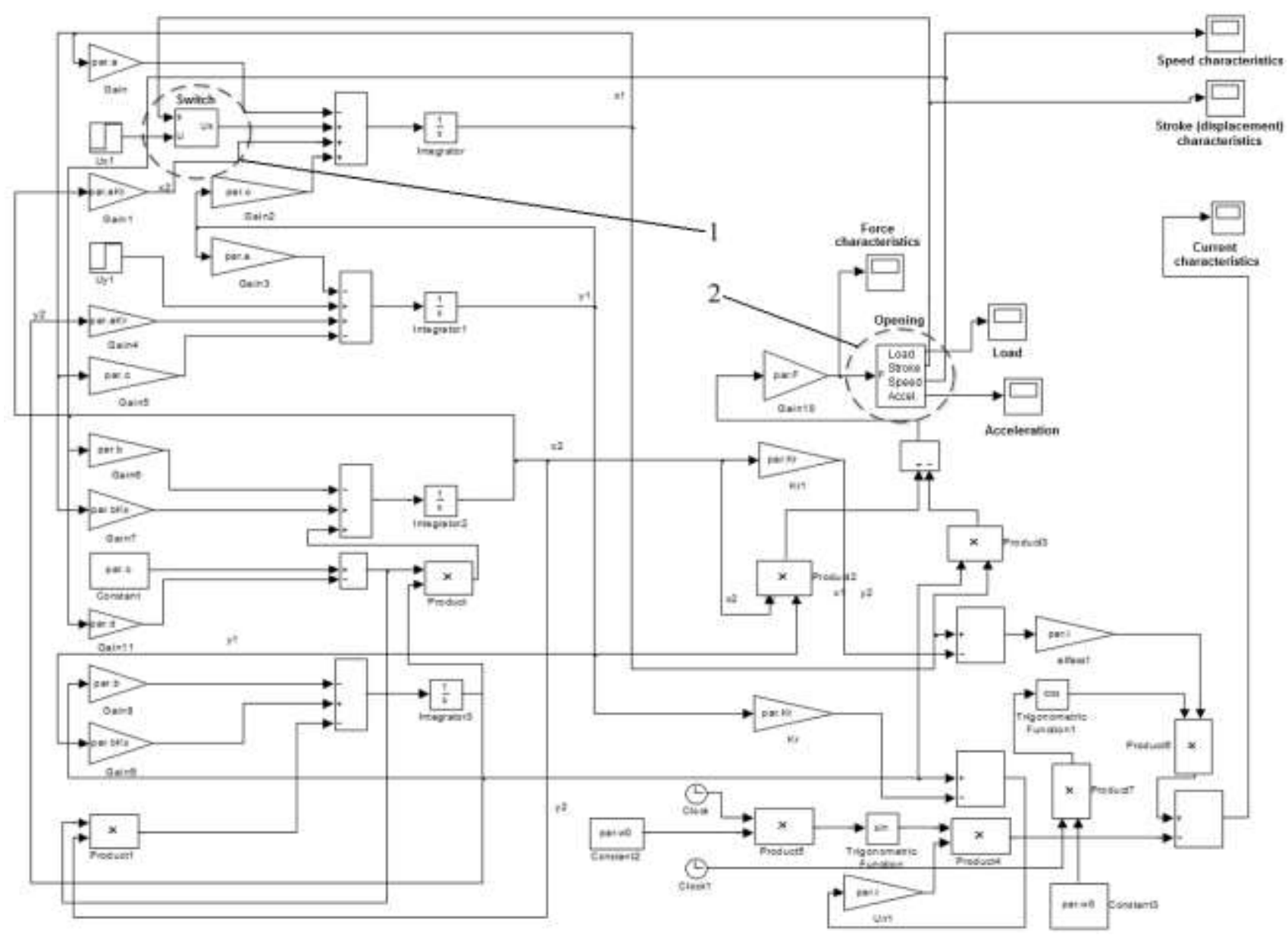

Fig. 8 Block diagram of the fire damper LIM computer model: 1 - power supply disconnection (PSD) block; 2 - resistance force evaluation (RFE) block

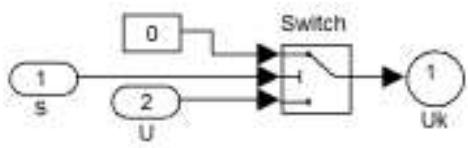

Fig. 9 Fire damper LIM computer model Power supply disconnection (PSD) block: $S$ - blade stroke (displacement); $U$ - power supply network voltage; $U k$ - fire damper LIM voltage 


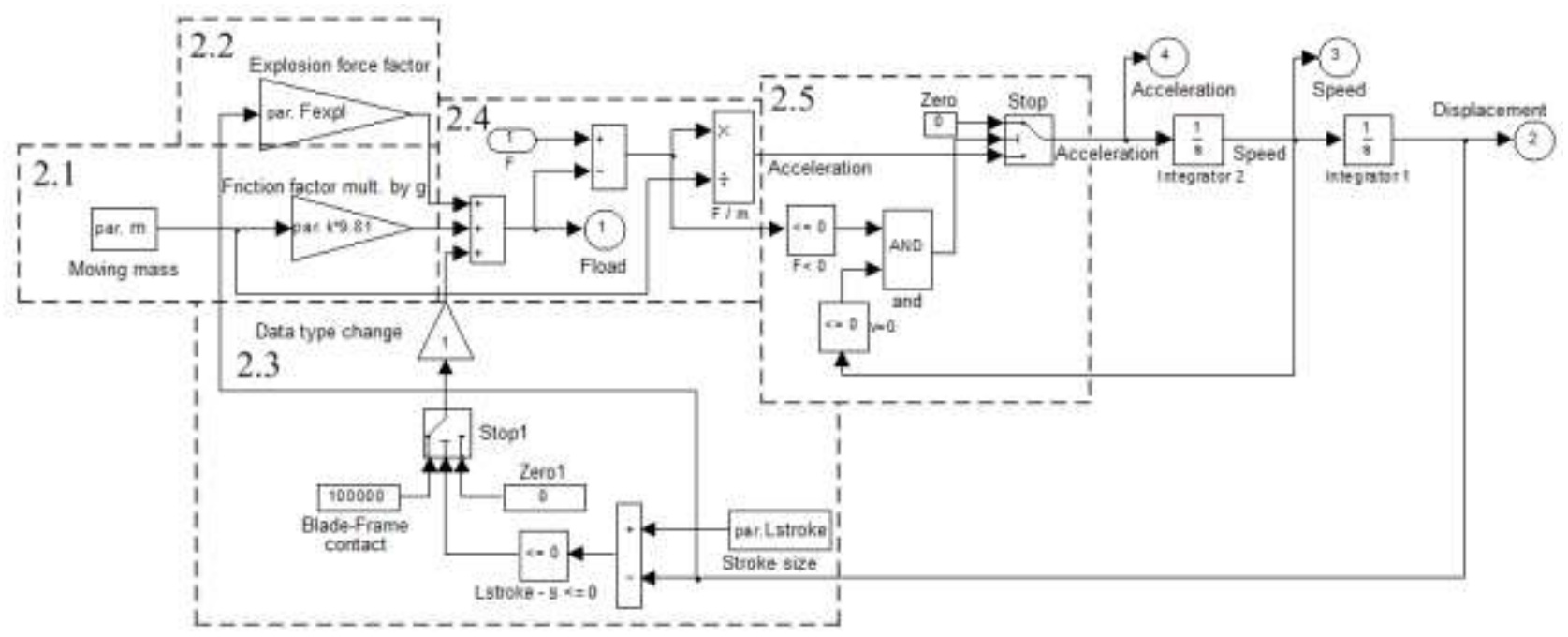

Fig. 10 Fire damper LIM computer model Resistance force evaluation (RFE) block: 2.1 - model of static resisting force; 2.2 - model of the dynamic resistance force caused by explosion; 2.3 - lade's edge impact to the guiding's frame body force model; 2.4 -resultant (effective) force model; 2.5 -blade (connected to LIM's secondary element) stopping model

Dynamic characteristics of all four designs slidegate type fire dampers (single, two (parallel and opposite) and four blades), having the same, $1 \times 1 \mathrm{~m}^{2}$ effective area was carried out by was investigated by using the abovementioned computer model of the fire damper linear induction motor (LIM) (Fig. 8). Variation of the driving force generated by LIM's of fire dampers, resistance force and blades displacement and speed over the time during closing the fire dampers was obtained (Figs. 11-18).

To compare in between four different designs of the dampers (having different number of blades moving in different directions, see section 3) it was assumed that all four dampers blades are actuated by 4 LIMs: in case of damper having single blade all four LIMs drive one $1 \mathrm{~m}^{2}$ size blade, in the dampers with 2 blades $0,5 \mathrm{~m}^{2}$ size each both of them are driven by two LIMs, and in the damper where four $0,5 \times 0,5 \mathrm{~m}^{2}$ size blades are used each of them are actuated by one LIM.

Dynamic characteristics (LIM generated force) of all four designs (or blades sizes) slide-gate type fire dampers are shown on Figs. 11 (the same, $6 \mathrm{~mm}$ thickness blades) and 12 (minimized thickness blades: correspondingly 6, 0,7, 2 and $0,5 \mathrm{~mm}$, see section 3 ).

As it may be seen from the Fig. 11, the smallest duration of shutting process $(0,36 \mathrm{~s})$ is obtained in case of 2nd and 4th construction dampers ( 2 and 4 blades) having smaller, $0,5 \mathrm{~m}$ stroke (blades moving oppositely). In remaining cases ( $1 \mathrm{~m}$ stroke, blades moving in parallel) $0,54 \mathrm{~s}$ is necessary to shut off the fire damper. The largest, $240 \mathrm{~N}$ steady force has to be applied to move the largest, $1 \mathrm{~m}^{2}$ size blade, and reduction of blade size cuts the damper shut off force proportionally. Force characteristic of 2 nd construction damper near $2 / 3$ of stroke (to $0,36 \mathrm{~s}$ ) coincides with the characteristic of 3rd construction damper (because both dampers are driven by the same couple of LIMs), but due to larger stroke prolongs further to $0,54 \mathrm{~s}$.

Results of computations presented on Fig. 12 show that minimization of blades thickness reduces the dampers shut off time quite significantly: in case of 2 nd and 4th construction dampers - more than in half (stroke timedrops from 0,54 to 0,26 and from 0,36 to $0,14 \mathrm{~s}$ correspondingly), for 3rd construction damper shut of time reduction is smaller (from 0.36 to $0.22 \mathrm{~s}$ ). Decrement of the size of LIMs force is not so distinct, near $30 \%$ (from $60-150 \mathrm{~N}$, see Fig. 11, to 40-100 N).

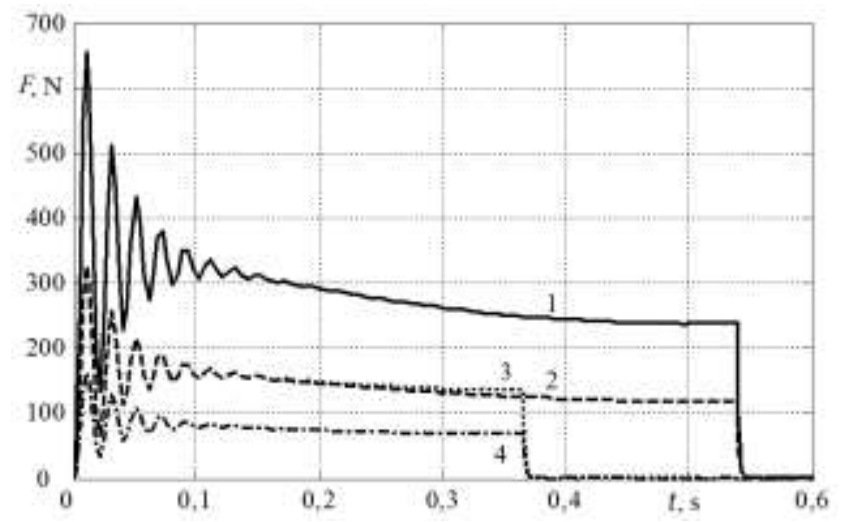

Fig. 11 Force generated by different construction slide-gate type fire dampers LIMs (in all cases the same $6 \mathrm{~mm}$ blade thickness): 1 -single blade; 2 -two blades moving in parallel; 3 - two blades moving oppositely; 4 - four blades

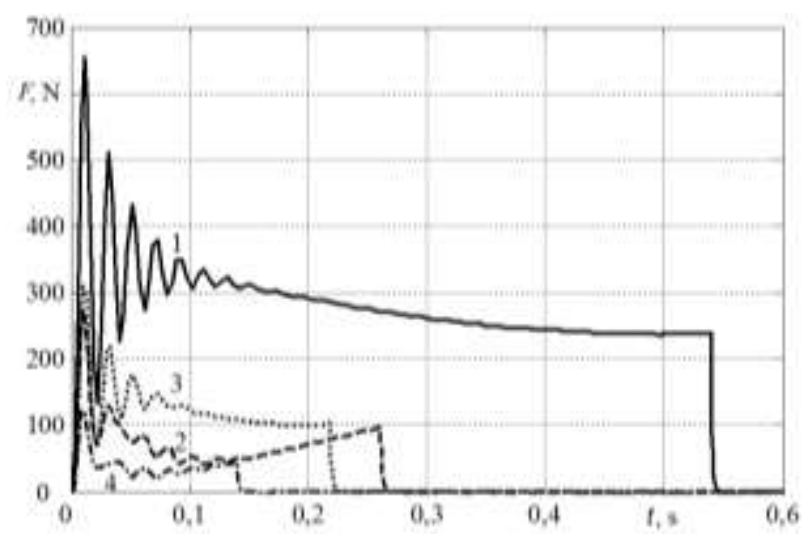

Fig. 12 Force generated by different construction slide-gate type fire dampers LIMs in case of the minimized thickness blades: 1 - single blade; 2 - two blades moving in parallel; 3 - two blades moving oppositely; 4 -four blades (blades thickness 6, 0,7, 2 and $0,5 \mathrm{~mm}$ correspondingly) 
Resistance force characteristics of different construction fire dampers moving element (blade, connected to LIM's secondary element) effected by explosion wave pressure are presented on Figs. 13 and 14 (the same, $6 \mathrm{~mm}$, and minimized $(6,0,7,2$ and $0,5 \mathrm{~mm})$ blades thickness correspondingly). Respectively to the curves illustrating LIMs shutting forces discussed above resisting forces are maximal and act longer for largest size and stroke $6 \mathrm{~mm}$ thickness blade damper (near $260 \mathrm{~N}$ and 0,54 s), while the same thickness quarter size blades induce $60 \mathrm{~N}$, or 4,3 times smaller resisting force (at the end of stroke) (Fig. 13). Minimization of blade thickness leads to the decrement of stroke time, but size of resisting force at the end of stroke remains practically the same.

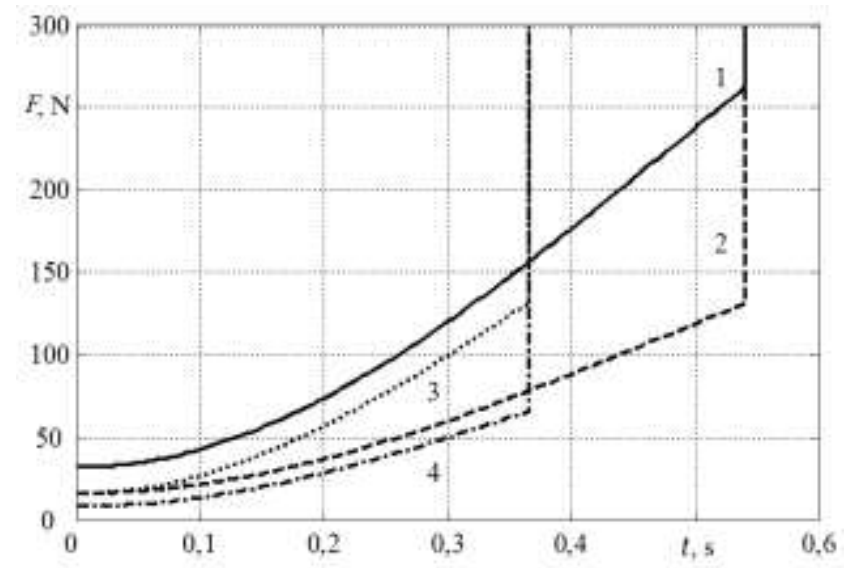

Fig. 13 Resisting force in different construction slide-gate type fire dampers: (in all cases the same $6 \mathrm{~mm}$ blade thickness): 1 - single blade; 2 - two blades moving in parallel; 3 - two blades moving oppositely; 4 - four blades

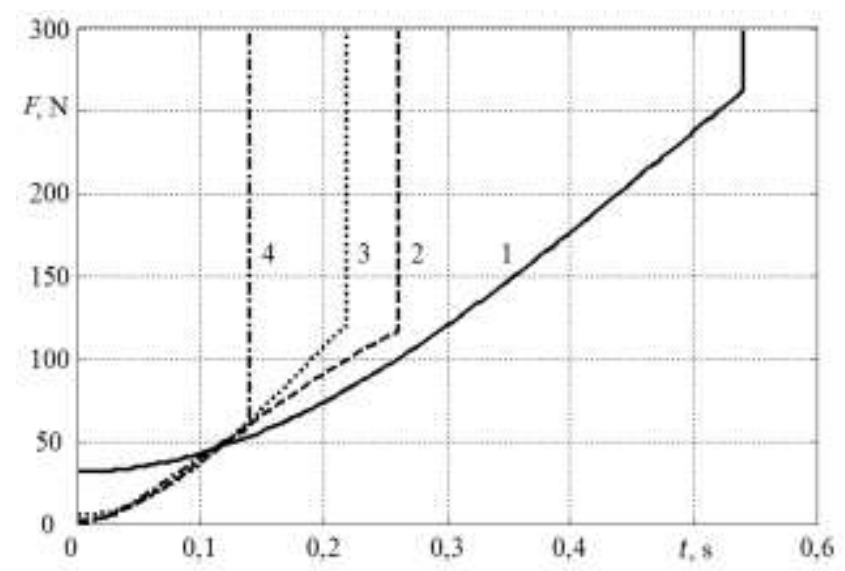

Fig. 14 Resisting force in different construction slide-gate type fire dampers in case of the minimized thickness blades: 1 - single blade; 2 - two blades moving in parallel; 3 - two blades moving oppositely; 4 - four blades (blades thickness 6, 0,7, 2 and 0,5 mm correspondingly)

Figs. 15 and 16 show slide-gate type fire dampers LIMs driven blades speed characteristics during damper shut off (Fig. 15 - the same $6 \mathrm{~mm}$, blade thickness dampers, Fig. 16 - minimized blades thickness dampers, see section 3 ).

It may be seen from Fig. 15 that the same $6 \mathrm{~mm}$ thickness blades speed characteristics are identical for dampers with the same stroke size ( $1 \mathrm{~m}$ for 1 st and 2 nd constructions dampers and $0,5 \mathrm{~m}$ for $3 \mathrm{rd}$ and 4 th constructions dampers), and all four curves are of very similar shape showing decreasing growth of the blade speed up to $2,2-2,7 \mathrm{~m} / \mathrm{s}$.

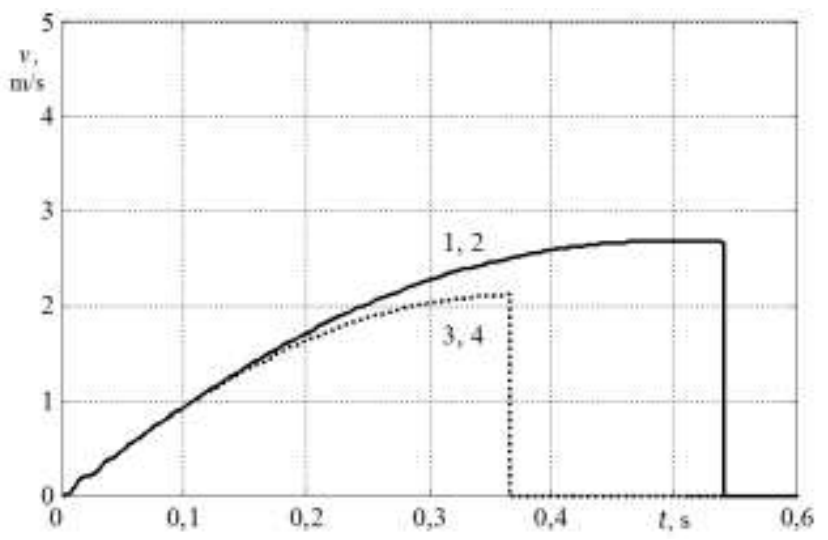

Fig. 15 Different construction slide-gate type fire dampers LIMs driven blades speed characteristics (in all cases the same $6 \mathrm{~mm}$ blade thickness): 1 - single blade; 2 -two blades moving in parallel; 3 -two blades moving oppositely; 4 - four blades

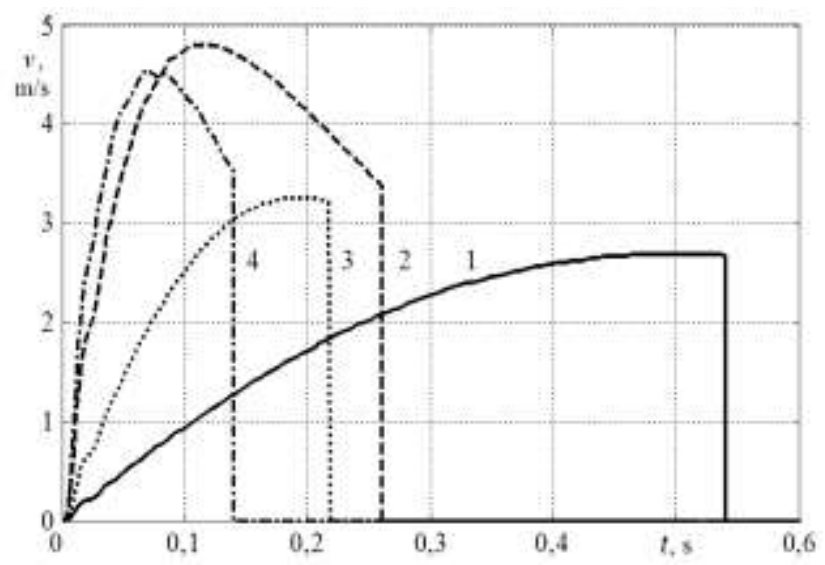

Fig. 16 Different construction slide-gate type fire dampers LIMs driven blades speed characteristics in case of the minimized thickness blades: 1 -single blade; 2 - two blades moving in parallel; 3 - two blades moving oppositely; 4 -four blades (blades thickness $6,0,7,2$ and $0,5 \mathrm{~mm}$ correspondingly)

Speed characteristics of the dampers with minimized thickness blades (Fig. 16, curves 1-3) clearly show the peaks of speed at the middle of the stroke for the 2 nd and 4th constructions dampers, reaching 4,5-4,8 m/s in comparison with $2,2-2,7 \mathrm{~m} / \mathrm{s}$ for dampers with $6 \mathrm{~mm}$ thickness blades (Fig. 15). To the end of stroke speed decreases, but still remains quite large, near $3,5 \mathrm{~m} / \mathrm{s}$. Of course, this fact means higher intensity impact of the blade into the damper's frame, but such event takes place extremely rarely and due to smaller thickness of the blade its mass is also smaller, so such impact loading should not decrease longevity of the damper.

\section{Conclusions}

It may be stated basing on the results of performed computer aided research that multi-blade design of 
the slide-gate type fire dampers for large cross-section ductworks allows to reduce the damper shut off time near 1,5 times when using the same thickness sheet type blade and more than 4 times when thickness of the blade is minimized to be able to withstand equivalent loading of explosion wave pressure. Such an improvement is conditioned by reduction of the blade stroke and mass of moving elements: in case of $1 \times 1 \mathrm{~m}^{2}$ cross-section ductwork substitution of single $1 \times 1 \mathrm{~m}^{2}$ size blade by four $0,5 \times 0,5 \mathrm{~m}^{2}$ blades (two pairs moving oppositely) cuts stroke of blades in half and reduces mass of moving elements near 16 times.

\section{References}

1. Vasilyev, J.J.; Semyonov, L.I. 1983. Explosion safety in enterprises of grain storage and processing, Moscov, Kolos, 224p. (in Russian).

2. Semyonov, L.I.; Tesler, L.A. 1991. Explosion safety of elevators, flour mills and feed mills, Moscow, Agropromizdat, 367p. (in Russian).

3. Muravyov, S.D.; Bukhantzov, A.V. 2011. Lights up or explodes dust in a state aerosuspension, Collection of 90 scientific papers of Lviv State University of Life Sagety, Fire safety, No. 19: 89-94 (in Russian).

4. Caution - grain dust. [accessed 05 January 2015]. Available from Internet: http://www.fumigaciya.ru/ sites/default/files/public/page/2013-01/315/ ostorozhnozernovayapyl.pdf (in Russian).

5. Knapp, J. 2011. Fire dampers and smoke dampers: the difference is important, AMCA International inmotion, Supplement to ASHRAE Journal, 20-23.

6. Fire and smoke dampers [accessed 05 January 2015]. Available from Internet: http://www.komfovent.com /fire-and-smoke-dampers.

7. Dampers [accessed 05 January 2015]. Available from Internet: $\quad$ http://www.joinersystems.com/Enviro_ Dampers.htm.

8. High-speed fire dampers of BZB series. [accessed 05 January 2015]. Available from Internet: http://www. stavemz.ru/catalog/zadvizhki-bystrodejstvuyuschie- serii-bzb-product-42.html (in Russian).

9. Rinkevičienė, R.; Poška, A.J.; Smilgevičius, A. 2006. Linear Mechatronic Systems: Theory and Application: Monograph. Vilnius Gediminas Technical Universitety. - Vilnius: Technika. 224p (in Lithuanian).

10. Budig, P.-K. 2000. The application of linear motors, Proceedings of the Third International Power Electronics and Motion Control Conference 3: 1336-1341. http://dx.doi.org/10.1109/IPEMC.2000.883044.

11. Rinkevičienė, R.; Savickienė, Z.; Poška, A.J. 2012. Performance of linear electric drive at localizing of dust explosions, Electronics and Electrical Engineering, 101-104. http://dx.doi.org/10.5755/j01.eee.122.6.1831.

\section{Eidukynas, A. J. Poška, V.Grigas}

\section{DYNAMICS OF THE LARGE OPENING FIRE VALVES OF DUST EXPLOSIONS AUTOMATIC LOCALIZATION SYSTEMS}

\section{S u m m a r y}

The paper analyzes the possibility to use automatic slide-gate type fire dampers with multiple blades superposed with the linear induction motor secondary elements in dust explosions localization systems with large crosssection ductworks. Sheet metal type blades stress-strain state computations by means of finite element method and studies of dynamics of fire dampers linear electric actuators by means of Matlab Simulink computer model were performed. It was obtained that the dampers blades thickness minimization reduces their response time about two times, closing force - near $30 \%$.

Keywords: fire damper, blade deformation, dynamics.

Received April 14, 2015 Accepted June 23, 2015 